\title{
Evaluation of LED application in general lighting
}

\author{
Muqing Liu \\ Fudan University \\ Department of Light Sources and Illuminating \\ Engineering \\ 220 Handan Road \\ Shanghai 200433, China \\ E-mail: mqliu@fudan.edu.cn
}

\section{Bifeng Rong}

Huub W. M. Salemink

Delft University of Technology

Faculty of Applied Science

Kavli Institute of Nanoscience

Lorentzweg 1

2628 CJ, Delft, The Netherlands

\begin{abstract}
This article analyzes the efficacy of the light sources and their limitations in theory and in technology. The LED's spectra were simulated by a Gaussian model to calculate the efficacy. The conventional light sources have been compared with LEDs; the results show that significant increase of LEDs' internal quantum efficiency and extraction efficiency is essential for LED application in general lighting. () 2007 Society of Photo-Optical Instrumentation Engineers. [DOI: 10.1117/1.2752500]
\end{abstract}

Subject terms: LED; general lighting; efficacy.

Paper 060715R received Sep. 12, 2006; revised manuscript received Dec. 29, 2006; accepted for publication Jan. 28, 2007; published online Jul. 2, 2007.

\section{Introduction}

Power consumption for illumination is increasing every year. However, the resources to produce electricity on earth are facing shortage in the long term. Among light sources, the light emitting diode (LED) is the most attractive because of its low power consumption and low operation voltage. The LED has developed rapidly in available emission spectrum and applications. These improvements, coupled with the inherent properties of solid-state devices (small package size, high reliability, low cost, and long operating time), have extended the LED into niche lighting applications, such as commercial advertising, automobile lights, large truck and bus lights, exit signs, traffic signals, and holiday lights. In all these cases, LEDs are replacing conventional lamps.

The most exciting and ambitious application for LEDs is general illumination on a large scale. There are many positive reports on the advantages of LEDs for general lighting. ${ }^{1-4}$ This article analyzes the efficacy of conventional lighting sources and LEDs, and evaluates LEDs' prospective application to general lighting in comparison with conventional light sources.

\section{The Definition of Efficacy}

The efficacy of light sources is the ratio of the total luminous flux emitted by the lamp and the total input power. It is expressed in lumens per watt $(\mathrm{lm} / \mathrm{W})$. For fluorescent and high-intensity discharge (HID) sources, the associated ballast power should be included in determining the general efficacy. The expression for the efficacy is

$$
\begin{aligned}
\eta & =\frac{F_{v}}{P_{l}}=\frac{K_{m} \int_{380}^{780} P_{\lambda} V(\lambda) \mathrm{d} \lambda}{P_{l}} \\
& =\frac{P_{0}}{P_{l}} \cdot \frac{\int_{0}^{\infty} P_{\lambda} \mathrm{d} \lambda}{P_{0}} \cdot \frac{\int_{380}^{780} P_{\lambda} \mathrm{d} \lambda}{\int_{0}^{\infty} P_{\lambda} \mathrm{d} \lambda} \cdot \frac{K_{m} \int_{380}^{780} P_{\lambda} V(\lambda) \mathrm{d} \lambda}{\int_{380}^{780} P_{\lambda} \mathrm{d} \lambda}
\end{aligned}
$$$$
=\eta_{b} \eta_{r} \eta_{v} K,
$$

$\eta_{b}=\frac{P_{0}}{P_{l}}$

$\eta_{r}=\frac{\int_{0}^{\infty} P_{\lambda} \mathrm{d} \lambda}{P_{0}}$,

$\eta_{v}=\frac{\int_{380}^{780} P_{\lambda} \mathrm{d} \lambda}{\int_{0}^{\infty} P_{\lambda} \mathrm{d} \lambda}$,

$$
K=\frac{K_{m} \int_{380}^{780} P_{\lambda} V(\lambda) \mathrm{d} \lambda}{\int_{380}^{780} P_{\lambda} \mathrm{d} \lambda},
$$

where $F_{v}$ is the total photometric flux; $P_{l}$ is the total power consumed by the lamp and the ballast; $P_{0}$ is the power consumed by the lamp; $P_{\lambda}$ is the spectral radiant flux; $V(\lambda)$ is the photometric spectral luminous efficiency; $K_{m}$ is the ratio of the radiometric to the photometric flux; $1-\eta_{b}$ is the

0091-3286/2007/\$25.00 @ 2007 SPIE 
proportion of power consumed by the ballast, which does not contribute to the total photometric flux $F_{v} ; \eta_{r}$ is the ratio of the radiant flux to the power consumed by the lamp; $\eta_{v}$ is the ratio of the visible radiation to the radiation in full spectrum; and $K$ is the luminous efficacy of the radiation. The efficacy $K$ reaches its theoretical maximum when $\eta_{b} \eta_{r} \eta_{v}=1$. This means that the input power is completely converted to visible light.

The value of $\eta_{b}$ is about 0.9 for the fluorescent and HID sources, and 1 for the incandescent lamp. Thus, the approximate value 1.0 is used here. Therefore, Eq. (1) can be simplified to

$\eta=\eta_{r} \eta_{v} k$

The quantities $\eta, \eta_{v}$, and $K$ can be measured; then $\eta_{r}$ can be calculated by using Eq. (6).

\section{The Efficacy of the Conventional Light Sources}

Currently the main light sources used for general lighting are the incandescent lamp, fluorescent lamp, high-pressure sodium lamp, and metal halide lamp. Several samples from different manufacturers with different color temperatures $\left(T_{c}\right)$ for every kind of light source have been characterized. The compact fluorescent lamp (the energy-saving lamp) has been tested as the fluorescent lamp in our experiments. Figure 1 shows typical spectral power distributions for each kind of light sources.

We have measured the power consumed in the lamps, the photometric flux, and the spectral power distribution curve in the range of wavelength 380 to $1700 \mathrm{~nm}$. Then $K$, $\eta_{v}, \eta$, and $\eta_{r}$ can be extracted by the definition. The data are listed in Table 1, where $\mathrm{Ra}$ is the color rendering index.

In the case of an incandescent lamp, the operation mechanism is thermal radiation. The temperature of its filament is higher than $2600 \mathrm{~K}$. This results in a high heat loss $\left(\eta_{r}=47.5 \%\right)$ and about $80 \%$ infrared light $\left(\eta_{v}=20.8 \%\right)$. Consequently the proportion of visible radiation is small. Thus the efficacy of the incandescent lamp is low. There are some efforts to increase $\eta_{v}$ by reflecting the infrared light back from bulb to filament. However, it does not increase the efficacy significantly. In the case of a fluorescent lamp, $82.7 \%$ of its radiation is the visible light, and high temperature is not required. The limitation on increasing its efficacy is the phosphor conversion efficiency (PCE). In the cases of a high-pressure sodium lamp or metal halide lamp, about $70 \%$ of their radiation is the visible light; however, further increase in their efficacy is limited by the heat loss $\left(\eta_{r}\right)$, because high temperature is needed for their operation, and that means high heat loss. ${ }^{5}$ Therefore, no substantial progress in increasing efficacy is expected for the four conventional light sources.

\section{The Efficacy of an LED}

For an LED, $\eta_{v}$ is 1 , since an LED designed for lighting emits light entirely in the visible range. Here $\eta_{r}$ is the external quantum efficiency (EQE). Therefore, the efficacy of an LED can be expressed as
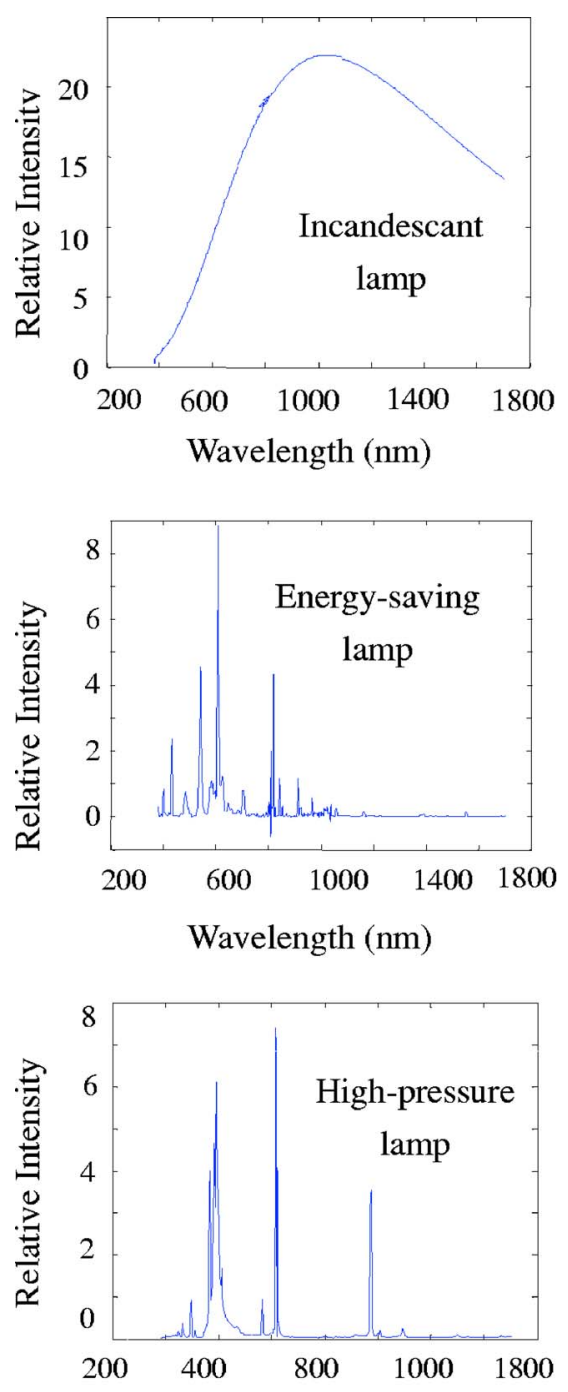

Wavelength $(\mathrm{nm})$

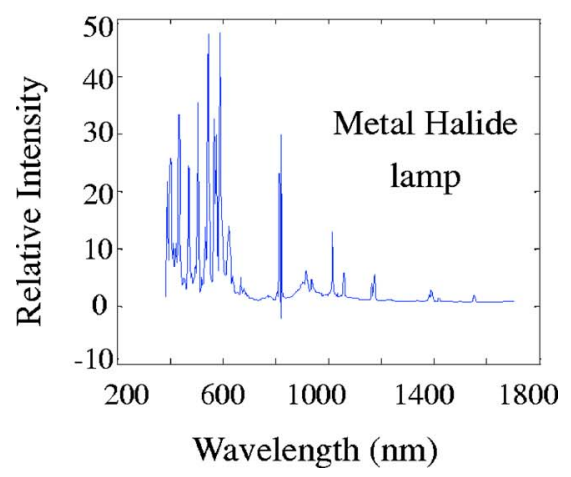

Fig. 1 Typical spectral power distributions of conventional light sources.

$\eta=\mathrm{EQE} \times K$.

The value of $K$ can be calculated from the spectrum of the LED. The EQE is the product of the internal quantum efficiency (IQE) and the light extraction efficiency (LEE). Thus, the efficacy of the LED is expressed as 
Liu, Rong, and Salemink: Evaluation of LED application...

Table 1 The efficacy of conventional light sources.

\begin{tabular}{lcccccccc}
\hline \hline Light source & $\begin{array}{c}\text { Power } \\
(\mathrm{W})\end{array}$ & $\begin{array}{c}\text { Flux } \\
(\mathrm{Im})\end{array}$ & $\begin{array}{c}\eta \\
(\mathrm{Im} / \mathrm{W})\end{array}$ & $\begin{array}{c}K \\
(\mathrm{Im} / \mathrm{W})\end{array}$ & $\begin{array}{c}\eta_{V} \\
(\%)\end{array}$ & $\begin{array}{c}\eta_{r} \\
(\%)\end{array}$ & $\mathrm{Ra}$ & $\begin{array}{c}T_{c} \\
(\mathrm{~K})\end{array}$ \\
\hline Incandescent & 99.5 & 1532 & 15.4 & 156 & 20.8 & 47.5 & 100 & 2805 \\
Energy-saving lamp & 22.5 & 1305 & 58 & 289 & 82.7 & 24.3 & 80.3 & 2418 \\
High-pressure sodium & 101.5 & 12383 & 122 & 338 & 76.3 & 47.3 & 20.2 & 1482 \\
Metal halide & 103.5 & 9915.3 & 95.8 & 288 & 69.8 & 47.7 & 72.8 & 3766 \\
\hline \hline
\end{tabular}

$\eta=\mathrm{IQE} \times \mathrm{LEE} \times K$.

\subsection{The Simulated and Measured LED Spectra}

Yoshi Ohno has reported a mathematical model (Gaussian model) for LED spectra with a relative expanded uncertainty of less than 5\% compared with the spectral power distribution of a typical real blue LED. ${ }^{6}$ We have measured numerous LEDs and used the same model to simulate their spectra. Figure 2 shows the measured spectra and simulated spectra for four color LEDs. By comparing the measured and the simulated spectrum, we calculated each LED's efficacy and chromaticity coordinates. Results are shown in Table 2. The subscript "real" denotes the value extracted from measurement spectra, while the subscript "simul" denotes the value extracted from the simulation spectra. From Fig. 2, it can be seen that the simulated spectra fit the measured spectra well. We have compared $K$ values and color coordinates extracted from the simulated and the measured spectra (shown in Table 2). The difference is so small that we use the simulation spectra for the further analysis instead.

\subsection{The Efficacy of the Color LEDs}

The state-of-the-art external quantum efficiency of highpower LEDs is shown in Fig. 3, which combines results from Nichia Chemical Co., CREE, and Lumileds Lighting. ${ }^{3}$ The LEE is dependent on the packaging technology. If we assume the LEE to be $50 \%$, which is the highest value achieved today, then we obtain internal quantum efficiencies of $69 \%, 10 \%$, and $85 \%$ for blue, green, and red LEDs, respectively. The efficacies of the color LEDs have been calculated and are listed in Table 3. They are comparable to the available data on the commercial products. ${ }^{7,8}$

\subsection{The Efficacy of the White LEDs}

Most of the lamps for artificial lighting are white or near white, similar to natural sunlight. Thus, we make the following assumption for white LEDs: The chromaticity coordinates $x, y, z$ are all 0.33 , and the average color rendering index is 80 or higher. Such light is called GLW (general lighting white) below. There are three main ways to manufacture a white-light LED:

1. Mix red LED, green LED, and blue LED light by packaging three color LEDs in one package, adjusting each LED power to produce white light. We call such a lamp an RGB-LED.
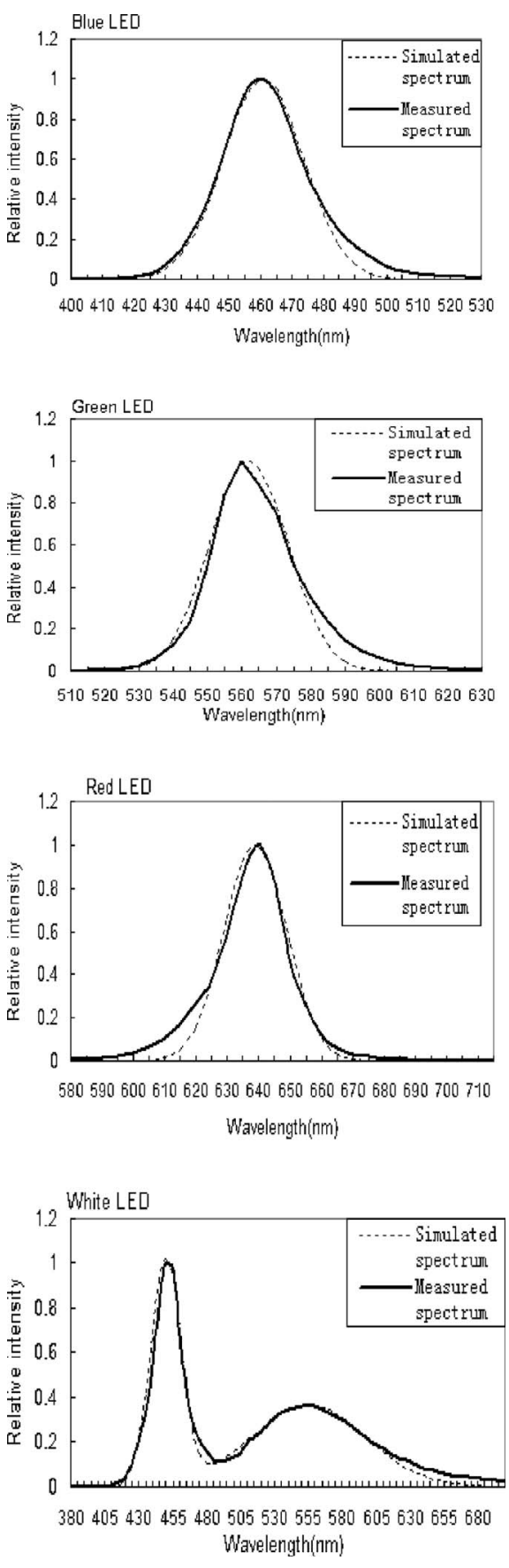

Fig. 2 The spectral power distribution of LEDs. 
Liu, Rong, and Salemink: Evaluation of LED application...

Table 2 Comparison between the simulated and the measured spectra.

\begin{tabular}{lrrrrrr}
\hline \hline & & & \multicolumn{5}{c}{ Color coordinates } \\
\cline { 3 - 7 } & & & & & & \\
\cline { 4 - 7 } $\begin{array}{l}\text { LED } \\
\text { nominal } \\
\text { wavelength) }\end{array}$ & $K_{\text {real }}$ & $K_{\text {simu }}$ & $X_{\text {real }}$ & $X_{\text {simu }}$ & $Y_{\text {real }}$ & $Y_{\text {simu }}$ \\
\hline Red $(640 \mathrm{~nm})$ & 147 & 128 & 0.70 & 0.71 & 0.30 & 0.29 \\
Green $(570 \mathrm{~nm})$ & 593 & 628 & 0.47 & 0.45 & 0.52 & 0.55 \\
Blue $(460 \mathrm{~nm})$ & 69 & 52 & 0.14 & 0.14 & 0.06 & 0.04 \\
White & 275 & 280 & 0.29 & 0.28 & 0.27 & 0.27 \\
\hline \hline
\end{tabular}

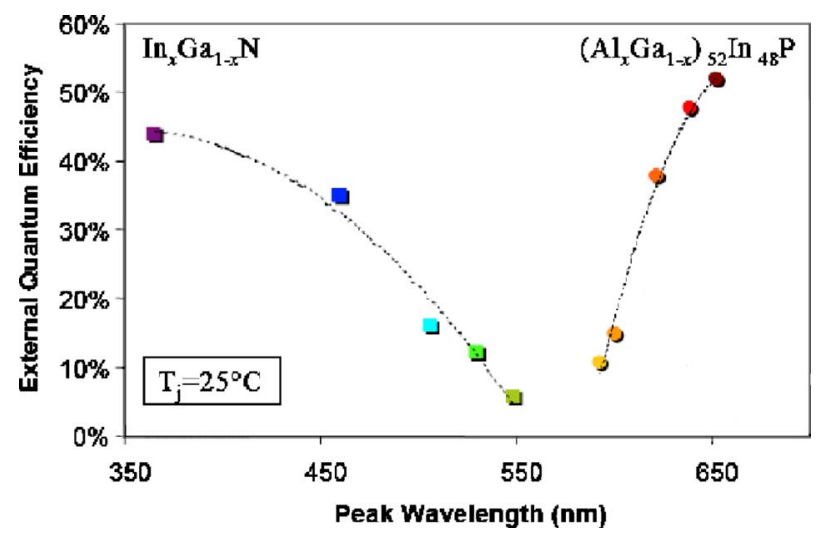

Fig. 3 External quantum efficiency versus peak wavelength.

Table 3 The efficacy of color LEDs.

\begin{tabular}{lccccc}
\hline \hline & $\begin{array}{c}K \\
\text { LED }(\text { nominal wavelength) }\end{array}$ & $\begin{array}{c}\text { IQE } \\
(\%)\end{array}$ & $\begin{array}{c}\text { LEE } \\
(\%)\end{array}$ & $\begin{array}{c}\text { EQE= IQE } \times \text { LEE } \\
(\%)\end{array}$ & General efficacy $(\mathrm{Im} / \mathrm{W})$ \\
\hline Red $(640 \mathrm{~nm})$ & 128 & 85 & 50 & 42.5 & 54 \\
Green $(570 \mathrm{~nm})$ & 628 & 10 & 50 & 5 & 31 \\
Blue $(460 \mathrm{~nm})$ & 52 & 69 & 50 & 34.5 & 18 \\
\hline \hline
\end{tabular}

Table 4 The efficacy of a white RGB-LED.

\begin{tabular}{lcccccccc}
\hline \hline & $\begin{array}{c}\text { Wavelength } \\
\text { Lectral width }) \\
(\mathrm{nm})\end{array}$ & $\begin{array}{c}K \\
(\mathrm{Im} / \mathrm{W})\end{array}$ & $\begin{array}{c}\text { IQE } \\
(\%)\end{array}$ & $\begin{array}{c}\text { LEE } \\
(\%)\end{array}$ & $\begin{array}{c}\text { EQE } \\
(\%)\end{array}$ & $\begin{array}{c}\text { Needed } \\
\text { input power } \\
(\mathrm{W})\end{array}$ & $\begin{array}{c}\text { Flux } \\
(\mathrm{Im})\end{array}$ & $\begin{array}{c}\text { General } \\
\text { efficacy } \\
(\mathrm{Im} / \mathrm{W})\end{array}$ \\
\hline Red & $614(20)$ & 312 & 85 & 50 & 42.5 & 2.4 & 312 & 39 \\
Green & $546(30)$ & 641 & 10 & 50 & 5.0 & 24.0 & 769 \\
Blue & $465(20)$ & 55 & 69 & 50 & 34.5 & 2.9 & 55 \\
\hline \hline
\end{tabular}

Table 5 The efficacy of a white RGB-LED with the assumption of improved LEE and IQE.

\begin{tabular}{lcccccccc}
\hline \hline LED & $\begin{array}{c}\text { Wavelength } \\
(\mathrm{nm})\end{array}$ & $\begin{array}{c}K \\
(\mathrm{~m} / \mathrm{W})\end{array}$ & $\begin{array}{c}\text { IQE } \\
(\%)\end{array}$ & $\begin{array}{c}\text { LEE } \\
(\%)\end{array}$ & $\begin{array}{c}\text { EQE } \\
(\%)\end{array}$ & $\begin{array}{c}P \\
(\mathrm{~W})\end{array}$ & $\begin{array}{c}\text { Flux } \\
(\mathrm{Im})\end{array}$ & $\begin{array}{c}\text { General } \\
\text { efficacy } \\
(\mathrm{m} / \mathrm{W})\end{array}$ \\
\hline Red & 614 & 312 & 85 & 70 & 59.5 & 1.7 & 312 & 146 \\
Green & 546 & 641 & 40 & 70 & 28.0 & 4.3 & 769 & \\
Blue & 465 & 54.5 & 80 & 70 & 56.0 & 1.8 & 54.5 & \\
\hline \hline
\end{tabular}


Table 6 The improved efficacy of a white PC-LED.

\begin{tabular}{|c|c|c|c|c|c|c|c|c|c|c|c|}
\hline LED & $\begin{array}{c}\lambda \\
(\mathrm{nm})\end{array}$ & $\begin{array}{c}\Delta \lambda \\
(\mathrm{nm})\end{array}$ & $\begin{array}{c}K \\
(\operatorname{Im} / \mathrm{W})\end{array}$ & $\begin{array}{l}\text { IQE } \\
(\%)\end{array}$ & $\begin{array}{l}\text { LEE } \\
(\%)\end{array}$ & $\begin{array}{c}\text { PCE } \\
(\%)\end{array}$ & $\begin{array}{l}\text { Needed power } \\
\text { for white } \\
\text { light } \\
\text { (W) }\end{array}$ & $\begin{array}{l}\text { Needed } \\
\text { blue } \\
\text { Light } \\
\text { (W) }\end{array}$ & $\begin{array}{l}\text { Total } \\
\text { blue } \\
\text { light } \\
\text { (W) }\end{array}$ & $\begin{array}{l}\text { Input } \\
\text { power } \\
\text { (W) }\end{array}$ & $\begin{array}{c}\text { General } \\
\text { Efficacy } \\
(\mathrm{Im} / \mathrm{W})\end{array}$ \\
\hline Blue & 455 & 25 & 36.8 & 69 & 50 & - & 0.36 & - & 2.9 & 8.3 & 55 \\
\hline Amber & 570 & 120 & 421 & - & - & 40 & 1.00 & 2.5 & & & \\
\hline \multicolumn{4}{|c|}{ Assumption } & 80 & 70 & 60 & - & - & 2.0 & 3.6 & 127 \\
\hline \multicolumn{4}{|c|}{ Theor. max. } & 100 & 100 & 80 & - & - & 1.6 & 1.6 & 284 \\
\hline
\end{tabular}

2. Coat a yellow phosphor on a blue LED. This is designed to leak some of the blue light beyond the phosphor to generate the blue portion of the spectrum, while the phosphor converts the rest of the blue light into the red and green portions of the spectrum. We call such a lamp a PC-LED.

3. Coat three kinds of phosphors on a UV LED. The phosphors generate red, green, and blue, respectively, and their mixture is white light. We call such a lamp a UV-LED. Ohno et al. have analyzed this type of LED ${ }^{6}$ and their results are similar to that for our PC-LED, which we analyze below. Hence we do not analyze the UV-LED here.

\subsubsection{RGB-LED}

We have used three primary color LEDs, as Tsao $\mathrm{did}^{2}$ to produce white light, and have used the simulation model to produce their spectrum. We have calculated that the power ratio of the three color LEDs (R:G:B) must be $1.0: 1.2: 1.0$ to produce GLW. Then we obtain the RGBLED's efficacies as shown in Table 4. In this case, the general efficacy is lower than that of energy-saving lamp, high-pressure sodium lamp, and metal halide lamp. If we can increase the LEE from $50 \%$ to $70 \%$, the IQE of the green LED from $10 \%$ to $40 \%$, and the IQE of the blue LED from $69 \%$ to $80 \%$, as listed in Table 5 , then we shall obtain a general efficacy of $146 \mathrm{~lm} / \mathrm{W}$, which is satisfactory. The RGB-LED's chromaticity coordinates are $(0.34,0.35)$, and the color rendering index is 87 . Therefore, this will be a good general lighting source. Furthermore, the maximum efficacy for the RGB-LED is $355 \mathrm{~lm} / \mathrm{W}$ when the IQE and the LEE are both $100 \%$ for all the color LEDs.

\subsubsection{PC-LED}

The PC-LED's spectrum is composed of the blue light and the amber light emitted from the phosphor excited by the blue light. We simulate two spectra to produce GLW. Then we obtain the PC-LED's luminous efficacy as shown in Table 6. Here we assume the central wavelength of the blue light is $455 \mathrm{~nm}$, and the spectral width $\Delta \lambda$ is $25 \mathrm{~nm}$. The central wavelength of amber light emitted from the phosphor is $570 \mathrm{~nm}$, and the spectral width is $120 \mathrm{~nm}$. These data are typical for this kind of white LED. It should be pointed out that the ratio of blue light to amber light has to be $0.36: 1$ to produce white light. The white light's chro- maticity coordinates are $(0.32,0.32)$, the color rendering index is 75, and the value of $K$ is $320 \mathrm{~lm} / \mathrm{W}$.

We assume that the IQE and the LEE are 69\% and 50\%, respectively (as in case of a blue LED). Given the general efficiency of $55 \mathrm{~lm} / \mathrm{W}$ (the best commercially available), we can obtain a PCE of $40 \%$. If we increase the IQE and the LEE to $80 \%$ and $70 \%$, respectively, as assumed for a PC-LED with a PCE of $60 \%$, then we obtain a general efficacy of $127 \mathrm{~lm} / \mathrm{W}$. This result still does not reach a satisfactory value. The maximum PCE is about $80 \%$, the ratio of the central wavelengths of blue light and amber light. With a IQE of $100 \%$ and a LEE of $100 \%$, we obtain the maximum general efficacy of the PC-LED as $284 \mathrm{~lm} / \mathrm{W}$.

It is obvious that a significant increase in general efficacy is necessary for LED application in general lighting. Several methods, such as applying photonic crystal, thinning the device layer thickness, and roughening the surface, have been reported to increase the efficacy. ${ }^{9,10}$ However, the white LED efficacy is still too low for general lighting application.

\section{Conclusion}

We have analyzed the efficacies of four conventional light sources: incandescent lamp, fluorescent lamp, highpressure sodium lamp, and metal halide lamp. Their efficacies are not expected to increase significantly, due to their radiation mode of operation.

The LED, as a potentially high-efficiency solid-state lighting source, may yet be a milestone in lighting history. However, from the analysis of its general efficacies, the conclusion is that a significant increase in extraction efficiency and internal quantum efficiency to increase the efficacy is essential for LED application in general lighting.

\section{References}

1. U. S. Department of Energy, "Illuminating the challenges-solid state lighting program planning workshop report" (2003).

2. J. Y. Tsao, "Solid-state lighting: lamp targets and implications for the semiconductor chip," IEEE Circuits Devices Mag. 8755-3996/04, 28-37 (2004).

3. M. G. Craford, "LEDs for solid state lighting and other emerging applications: status, trends, and challenges," Proc. SPIE 5941, 594101 (2005).

4. N. Narendran and L. Deng, "Performance characteristics of lighting emitting diodes," in Proc. IESNA Annual Conf., pp. 157-164 (2002).

5. Z. Cai, The Introduction to the Principle of Light Sources, Fudan Univ. Press, Shanghai (1988). 
6. Y. Ohno, "Spectral design considerations for white LED color ren*dering," Opt. Eng. 44(11), 1-9 (2005).

7. "Superflux LEDs," http:www.lumileds.com.

8. "X-Bright Plus LED specifications," http://www.cree.com.

9. A. David, T. Fujii, R. Sharma, K. Mcgroody, S. Nakamura, S. P. DenBaars, E. L. Hu, and C. Weisbuch, "Photonic-crystal GaN lightemitting diodes with tailored guided modes distribution," Appl. Phys. Lett. 88, 061124 (2006).

10. D.-H. Kim, C.-O. Cho, Y. G. Rha, H. Jeon, Y. S. Park, J. Cho, J. S Im, C. Sone, Y. Park, W. J. Choi, and Q.-H. Park, "Enhanced light extraction from GaN-based light-emitting diodes with holographically generated two-dimensional photonic crystal patterns," Appl. Phys. Lett. 87, 203508 (2005)

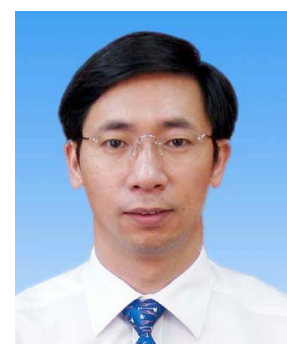

Muqing Liu has been director of the Institute of Electrical Light Sources at Fudan University since May 2004, and a full professor since 2002. He is a member of a scientific committee that runs a series of international symposia on science and technology of light sources, and of one of the academic committees of the Chinese national LED program. He joined Fudan University in 1988 and led a number of projects, such as methodology of light sources and instrumentation, and methods for measuring LEDs. He graduated from the Department of Optical Engineering of Zhejiang University, China, and has 12 Chinese patents.

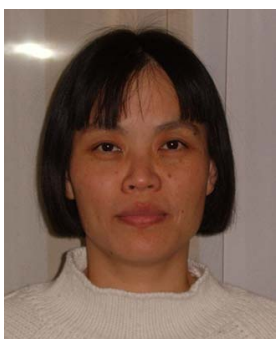

Bifeng Rong, received a BE from the Department of Material Science and Engineering, Zhejiang University, China in 1989; an ME from Shanghai Institute of Optics and Fine Mechanics, Academy of Science, China, in 1992; and a PhD from the Department of Electrical and Electronic Engineering, Canterbury University, New Zealand in 2001. She joined the lighting industry in 1993 and soon built up her own lighting businesses. In 2001 she worked in the Microelectronic Group at Southampton University as an experimental officer. Since 2002 she has worked at Delft University of Technology as a postdoc. Her current interests are photonic crystals and their applications, and III-V technology.

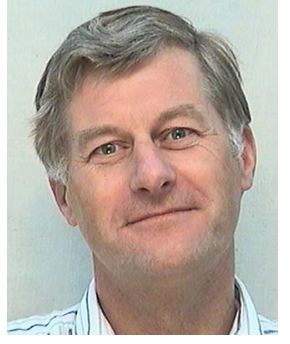

Huub W. M. Salemink has been, since the end of 2004, a full professor of nanophotonics and the chairman of the Department of Nanoscience at TU Delft. He is a board member of the nanotechnology consortium NanoNed in the Netherlands. From 1985 until his return to the Netherlands in 2001 he was a researcher at the IBM Zurich Research Laboratory in Switzerland, where he pioneered cross-sectional scanning tunneling microscopy and novel silicon-based photonic materials. From 2001 to 2004 he was a full professor of nanophotonics at TU Eindhoven. Before his departure to Zurich he was an employee in the Semiconductor Laser Department of Philips Research and worked on laser remote sensing at RIVM. His thesis and study in experimental solid state physics were at Radboud University in Nijmegen. He has (co)authored approximately 125 scientific papers and 12 IBM patents. 